\author{
Military Technical College \\ Kobry El-Kobbah, \\ Cairo, Egypt
}

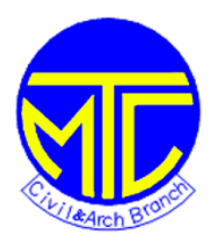

\title{
Experimental Investigation on Mechanical Properties of Shape Memory Alloy Fibre-Reinforced ECC Composite
}

\author{
By \\ Mohamed A.E.M. Ali* $\quad$ Moncef L. Nehdi**
}

\section{$\underline{\text { Abstract: }}$}

An innovative hybrid engineered cementitious composite (HECC-SMAF) incorporating randomly dispersed polyvinyl alcohol (PVA) and shape memory alloy short fibres (SMA) has been developed in this study. The behaviour of the composite produced with and without NiTi-SMA and/or polyvinyl-alcohol (PVA) short fibres was investigated. The experimental results show that utilizing a combination of those fibres can affect the composite by a slight to no increase in compressive strength while it can enhance the flexural capacity by up to $144 \%$. Also, a general reduction in workability was observed due to incorporating those fibres in the composite compared to that of the ECC matrix mixture.

\section{Keywords:}

Engineered cementitious composite, shape memory alloy, PVA, NiTi-SMA, fibres.

*Egyptian Armed Forces

**Western University, London, ON, Canada. 


\section{Introduction:}

Concrete has been utilized in construction for more than 5000 years. Concrete elements such as beams and slabs could be subjected to a combination of compressive and tensile loads due to the effects of dead and live loads, thermal shrinkage and expansions. In the last few decades, high-performance fibre-reinforced concrete (HPFRC) has been utilized in structural elements due to its superior resistance to tensile loads and environmental conditions.

Engineered Cementitious Composites (ECCs) are a special type of HPFRC, which have a tensile strain of more than 3\% (hundreds of times that of normal concrete) [11]. Polyvinyl alcohol, polypropylene, polyethylene, and steel fibres have been utilized in the production of ECCs. Unlike other cementitious materials, PVA-ECC displays a metal-like performance after first cracking and exhibits a greater strain capacity of about 500 times than that of normal concrete. In recent years, hybrid fibres have been utilized in cement-based composites to enhance their mechanical properties [10,13].

Investigating the effects of using shape memory alloys (SMAs) in civil engineering structures have been reported by many researchers, mostly utilizing SMA rods [9] or continuous wires [12]. However, information on using such a material in structural elements in the form of short fibres is still scarce.

This paper aims to investigate the effects of partial replacement of PVA fibres by $0.5 \%$ (volume fraction) NiTi-SMA fibres on the mechanical properties of PVA-ECC at testing ages of 3 and 28 days. The experimental testing parameters include flowability, compressive strength, load-displacement curves in flexure and strain recovery.

\section{Experimental program:}

\section{$\underline{2.1 \text { Materials }}$}

The cement used in the production of ECC mixtures was ordinary portland cement (OPC) corresponding to ASTM C150 [1] (Standard Specification for Portland Cement). It has a specific gravity and surface area of $3.15 \mathrm{~g} / \mathrm{cm}^{3}$ and $371 \mathrm{~m}^{2} / \mathrm{kg}$, respectively. Class-C fly ash (FA) meeting the requirements of ASTM C618 [8] (Standard Specification for Coal Fly Ash and Raw or Calcined Natural Pozzolan for Use in Concrete) with a lime content of $16 \%$ provided by the Lafarge Thermal Power Plant was also used. Chemical compositions of the cement and fly ash are displayed in Table 1. Micro-silica sand (SS) with a maximum particle size of $200 \mu \mathrm{m}$ and specific gravity of 2.65 was also utilized. 
Proceedings of the $\mathbf{1 1}^{\text {th }}$ ICCAE-11 Conference, 19-21 April, 2016

Table (1): Chemical composition of cement, fly ash, and silica sand

\begin{tabular}{|c|c|c|c|}
\hline $\begin{array}{c}\text { Component } \\
\text { (\%) }\end{array}$ & Cement & Fly ash & Silica sand \\
\hline $\mathbf{C a O}$ & 64.35 & 16.00 & 0.01 \\
\hline $\mathrm{SiO}_{2}$ & 20.08 & 52.19 & 99.70 \\
\hline $\mathbf{A l}_{2} \mathbf{O}_{3}$ & 4.63 & 17.56 & 0.14 \\
\hline $\mathbf{F e}_{\mathbf{2}} \mathbf{O}_{3}$ & 2.84 & 3.66 & 0.016 \\
\hline $\mathbf{M g O}$ & 2.07 & 1.57 & 0.01 \\
\hline $\mathbf{S O}_{3}$ & 2.85 & 2.40 & --- \\
\hline $\mathbf{K}_{\mathbf{2}} \mathbf{O}$ & --- & 0.90 & 0.04 \\
\hline $\mathbf{N a}_{2} \mathbf{O}$ & --- & 0.70 & 0.01 \\
\hline \hline Loss of ignition & 2.56 & 1.60 & --- \\
\hline
\end{tabular}

To obtain strain hardening performance, PVA fibres with a diameter of $39 \mu \mathrm{m}$, a length of $8 \mathrm{~mm}$, a tensile strength of $1620 \mathrm{MPa}$, elastic modulus of $42.8 \mathrm{GPa}$, maximum elongation of $6 \%$, and density of $1300 \mathrm{~kg} / \mathrm{m}^{3}$ were utilized. In addition, NiTi-SMA short fibres, which meet the ASTM F2063 [3] (Standard Specification for Wrought NickelTitanium Shape Memory Alloys for Medical Devices and Surgical Implants) specifications were used at $0.5 \%$ by volume fraction as partial replacement for PVA fibres. The SMA fibres have a diameter of $625 \mu \mathrm{m}$, a length of $16 \mathrm{~mm}$, tensile strength of $869 \mathrm{MPa}$, elastic modulus of $41 \mathrm{GPa}$, maximum elongation of 38\%, and density of $6450 \mathrm{~kg} / \mathrm{m}^{3}$. To improve the workability of the different ECC mixtures, polycarboxylate high-range water reducing admixture (HRWRA) according to ASTM C494 [6] (Standard Specification for Chemical Admixtures for Concrete) specifications was added as a percentage of cement weight as shown in Table 2.

Table (2): Mixture proportions

\begin{tabular}{|c|c|c|c|c|c||c|c|}
\hline Mixture & Cement & $\begin{array}{c}\text { Fly } \\
\text { ash }\end{array}$ & $\begin{array}{c}\text { Silica } \\
\text { sand }\end{array}$ & w/cm & HRWRA & $\begin{array}{c}\text { PVA } \\
\left(\mathbf{\% V}_{\boldsymbol{f}}\right)\end{array}$ & $\begin{array}{c}\text { SMA } \\
\left(\mathbf{\% V}_{\boldsymbol{f}}\right)\end{array}$ \\
\hline ECC0-0 & 1 & 1.2 & 0.8 & 0.26 & 0.012 & 0 & 0 \\
\hline ECC2-0 & 1 & 1.2 & 0.8 & 0.26 & 0.012 & 2 & 0 \\
\hline ECC1.5-0.5 & 1 & 1.2 & 0.8 & 0.26 & 0.012 & 1.5 & 0.5 \\
\hline
\end{tabular}


Table 2 displays the mixture proportions for all tested specimens. The first number in the abbreviation shows the PVA fibre content, while the second number indicates the SMA fibre content. For example, ECC1.5-0.5 refers to an engineered cementitious composite (ECC) incorporating 1.5\% PVA fibre and 0.5\% SMA fibre by volume fraction.

\subsection{Preparation, casting and curing}

Firstly, a $20 \mathrm{~L}$ mixer was used to mix the solid ingredients, including the cement, FA, and silica sand in dry condition for one minute. Then, water and the HRWRA were added to the dry mixture over another three minutes of mixing until a homogeneous consistency was produced. Thereafter, PVA and SMA fibres were added gradually and mixing resumed over another three minutes until all fibres were uniformly distributed. Finally, specimens for testing of mechanical properties were prepared by direct pouring of the mixture into molds without compaction. All specimens were demolded after $24 \mathrm{~h}$ and cured inside sealed plastic bags to avoid mixing water loss due to evaporation until the testing age.

\section{Measurements:}

\subsection{Workability}

To explore the effects of SMA and/or PVA fibre addition on the workability of ECC, a flow table test was carried out on freshly mixed ECC mixtures as per the guidelines of ASTM C230 [4] (Standard Specification for Flow Table for Use in Tests of Hydraulic Cement).

\subsection{Compressive strength}

From each ECC mixture, nine cubic specimens of $50 \mathrm{~mm}$ x $50 \mathrm{~mm}$ x $50 \mathrm{~mm}$ were prepared and tested at the ages of 3, 14 and 28 days for the determination of the compressive strength of the different ECC mixtures as per ASTM C39 [5] (Standard Test Method for Compressive Strength of Cylindrical Concrete Specimens). The compressive strength test was carried out on the cubic specimens using a compressive testing machine with a capacity of $2000 \mathrm{kN}$.

\subsection{Splitting tensile strength}

Six cylindrical specimens of $75 \mathrm{~mm}$ in diameter by $150 \mathrm{~mm}$ in height were produced and tested from each ECC mixture for the determination of the splitting tensile strength at the ages of 3 and 28 days as per ASTM C496 [7] (Standard Test Method for Splitting Tensile Strength of Cylindrical Concrete Specimens). 


\subsection{Flexural Performance}

For the determination of flexural capacity of ECC specimens, six prisms of $40 \mathrm{~mm} \times 80$ $\mathrm{mm} \times 360 \mathrm{~mm}$ were prepared from each ECC mixture as per the guidelines of ASTM C1609 [2] (Standard Test Method for Flexural Performance of Fibre-Reinforced Concrete - Using Beam with Third-Point Loading) at the testing ages of 3 and 28 days. The specimens were tested using a MTS machine with a capacity of $250 \mathrm{kN}$ under a loading rate of $0.05 \mathrm{~mm} / \mathrm{min}$. The number of cracks and their width were monitored after each test using an optical microscope. A heat treatment for 3 minutes was applied to the specimens after testing using a heat gun, which was fixed away at $35 \mathrm{~mm}$ from the specimen's cracked surface (tension side) to investigate the strain recovery performance of SMA fibres. The gun was able to heat the specimens up to $300^{\circ} \mathrm{C}$.

\section{Results and Discussion:}

\subsection{Workability}

According to the flow table test results, it can be observed that the ECC matrix mixture (control) had the ability to flow under its own weight. Generally, fibre addition led to an overall reduction in workability regardless of the fibre type. For example, as shown in Fig. 1, the workability of the ECC2-0 and ECC1.5-0.5 mixtures decreased by 5.6\% and $33.3 \%$, respectively, compared to that of the ECC0-0 matrix mixture. Likewise, for the same fibre content, it can be observed that partial replacement of PVA with SMA fibres also decreased the workability. For instance, due to the replacement of PVA with $0.5 \%$ SMA fibres by volume fraction, the workability decreased by about six times compared to that of the ECC mixture made with 2\% PVA fibre alone.

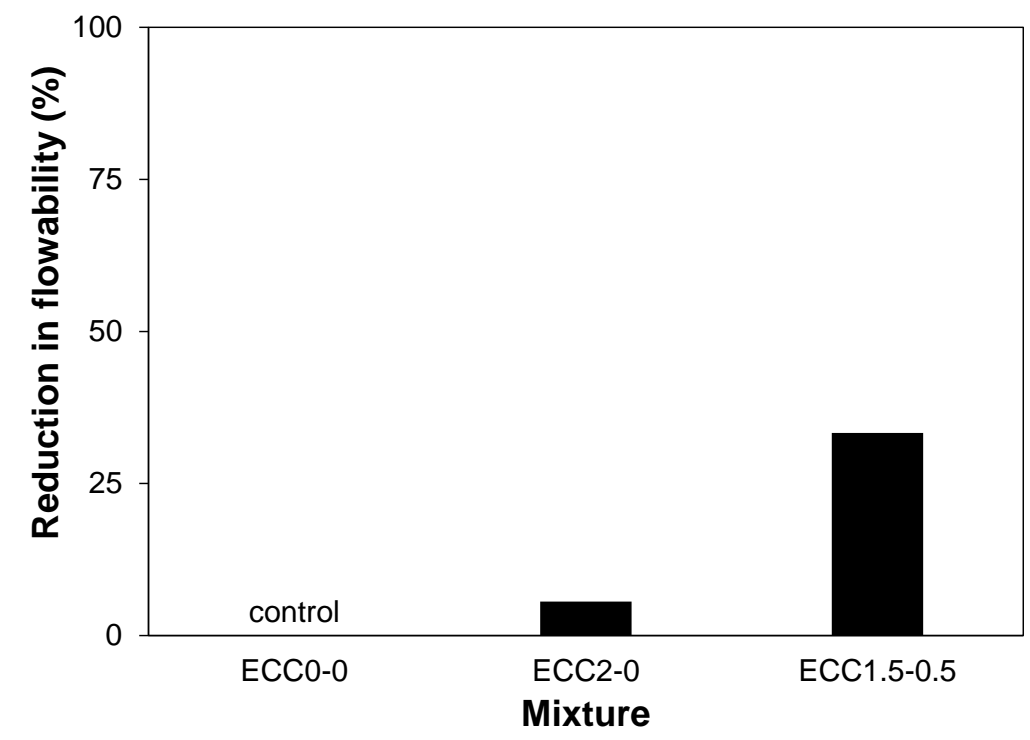

Figure (1): Reduction in flow diameter due to fibres addition. 


\subsection{Compressive strength}

The compressive strength of the ECC specimens at 3, 14 and 28 days was 40, 55 and 69 $\mathrm{MPa}$, respectively. The variation in the compressive strength test results is illustrated in Fig. 2. It can be observed that SMA and/or PVA fibre addition led to a slight to no increase in the compressive strength of the composite. For example, at 3 days, the compressive strength of the ECC2-0 and ECC1.5-0.5 mixtures slightly increased by about $7.9 \%$ and $5.2 \%$, respectively, compared to that of the ECC matrix mixture. The same performance was observed at 14 and 28 days, but with different percentages. For instance, the compressive strength of the ECC2-0, ECC1.5-0.5 mixtures slightly increased by about $7.8 \%$ and $5.6 \%$ at 14 days, respectively, and $8.7 \%$ and $4.8 \%$, respectively, at 28 days. On the other hand, the compressive strength slightly decreased due to the replacement of PVA with 0.5\% SMA fibres at all testing ages. For example, the compressive strength of the ECC1.5-0.5 mixture slightly decreased by about $2.6 \%$, $4.0 \%$ and $3.6 \%$ at testing ages of 3, 14 and 28 days, respectively, compared to that of the ECC mixture produced with 2\% PVA fibres alone at the same testing ages.

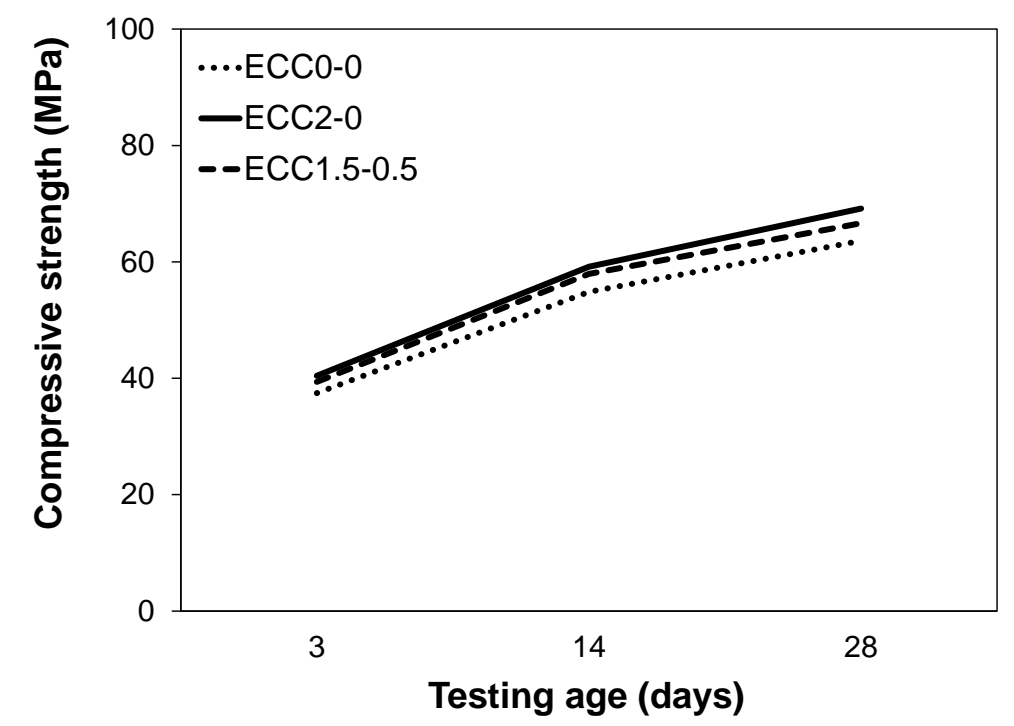

Figure (2): Compressive strength of ECC specimens.

\subsection{Splitting tensile strength}

Figure 3 illustrates the variation in the splitting tensile strength for the different ECC mixtures at the testing ages of 3 and 28 days. Generally, an enhancement in the tensile capacity of the composite was observed due to fibre addition regardless of the fibre type. For instance, the tensile capacity at 3 days of the ECC2-0 and ECC1.5-0.5 specimens was improved by up to 3 to 4 times that of the ECC0-0 mixture, respectively. 
This may be attributed to the high frictional bond strength of the fibre-matrix interfacial zone, which enhanced the overall tensile capacity of the composite. The same performance was observed at the testing age of 28 days. Partial replacement of PVA with $0.5 \%$ SMA fibres generally improved the tensile capacity of the composite at all testing ages. For instance, the ECC1.5-0.5 specimen had a tensile capacity of $7.8 \%$ and $10.9 \%$ at 3 and 28 days, respectively, higher than that of the ECC specimens that incorporated 2\% PVA fibres alone tested at the same ages.

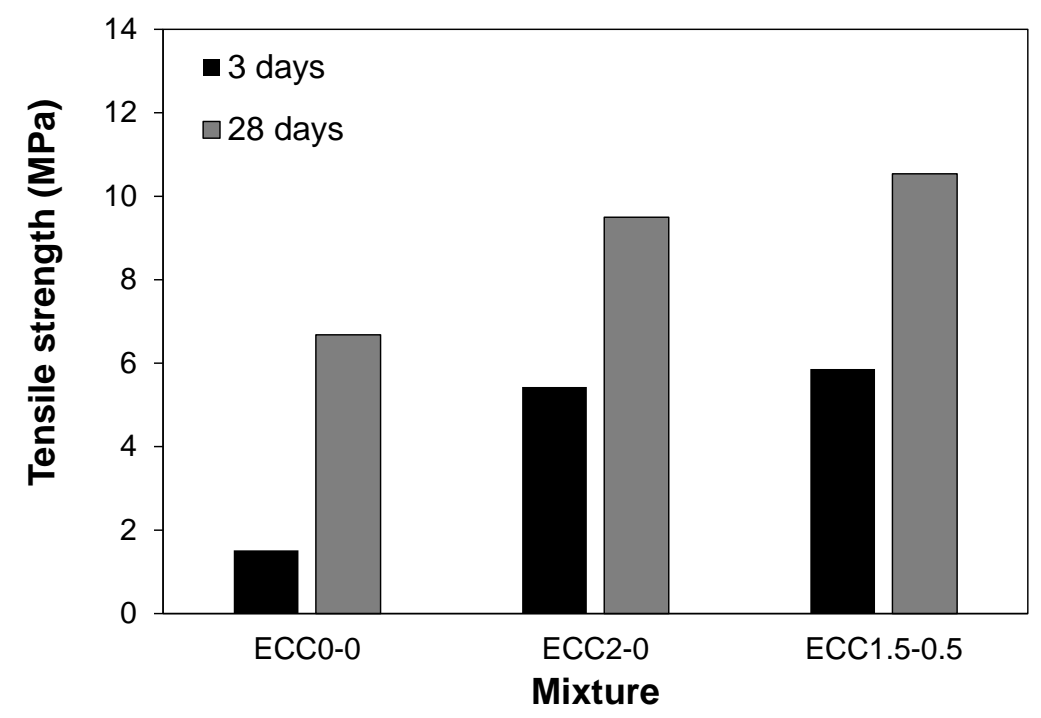

Figure (3): Splitting tensile strength of ECC specimens.

\subsection{Flexural performance}

\subsubsection{Flexural strength}

In this study, the peak load sustained by specimens and their crack pattern are the main parameters that have been investigated. Figure 4 illustrates the load-deflection curves of the different ECC mixtures tested under four-point bending at 3 and 28 days. It was observed that the flexural strength of the ECC specimens generally increased with fibre addition at all testing ages, regardless of the fibre type. However, for the same fibre content, the ECC specimens made with 2\% mono-PVA fibres exhibited higher flexural capacity at all testing ages than that produced with 1.5\% PVA and 0.5\% SMA fibres. 

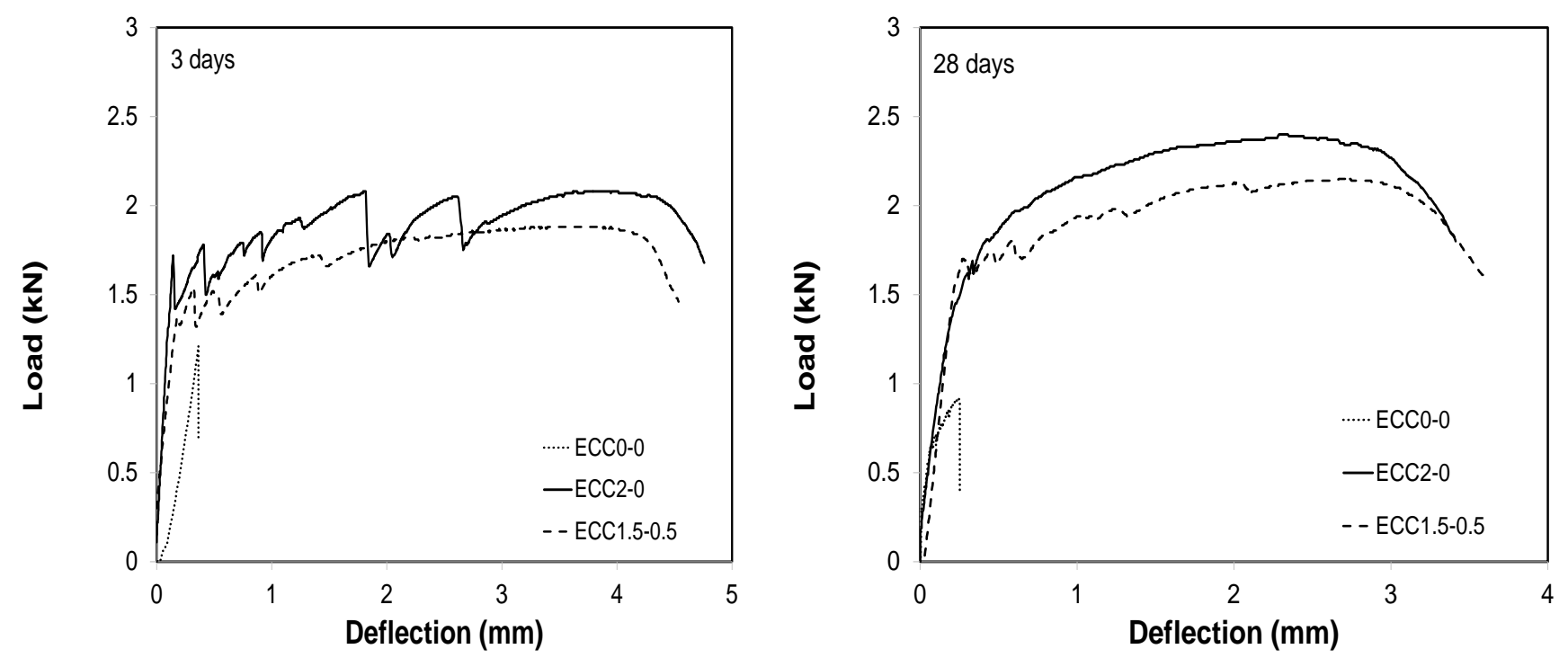

Figure (4): Load-deflection curves of ECC specimens at 3 and 28 days.

For instance, the ultimate flexural strength of the ECC2-0 and ECC1.5-0.5 specimens at 3 days was about $76.9 \%$ and $30.7 \%$ higher than that of the ECC matrix specimens, respectively. The same performance was observed at the age of 28 days but with different percentages. For example, the flexural capacity of the ECC2-0 and ECC1.5-0.5 specimens at 28 days was about $161.1 \%$ and $144.4 \%$ higher than that of the ECC0-0 mixture, respectively. This may be attributed to the high volume of fly ash which represents more than half of the total cementitious materials, which gained its strength at later ages, thus enhancing the fibre-matrix frictional bond resistance. The number of cracks formed on the tensile side of specimens was monitored after each test to evaluate the effect of fibres on the crack propagation within the composite. It was observed that specimens from all ECC mixtures had multi-fine cracks on the tensile face of the specimens with an average width of $100 \mu \mathrm{m}$, except that made from the matrix mixture (ECC0-0), which exhibited a brittle failure due to the absence of fibres. The ultimate flexural strength of ECC specimens varied from 2.3 to 6.0 MPa depending on the testing age and fibre content.

\subsubsection{Strain recovery}

The strain recovery characteristic was explored by applying heat treatment procedures immediately after removing the cracked ECC specimens from the flexural bending test. Although, this process was accompanied with a grid of multiple fine cracks (less than 10 $\mu \mathrm{m})$ at the tensile face of the specimens and the combustion of PVA fibres, the existing cracks were self-healed due to shape memory effect of NiTi-SMA fibres utilized in the ECC1.5-0.5 mixture. 


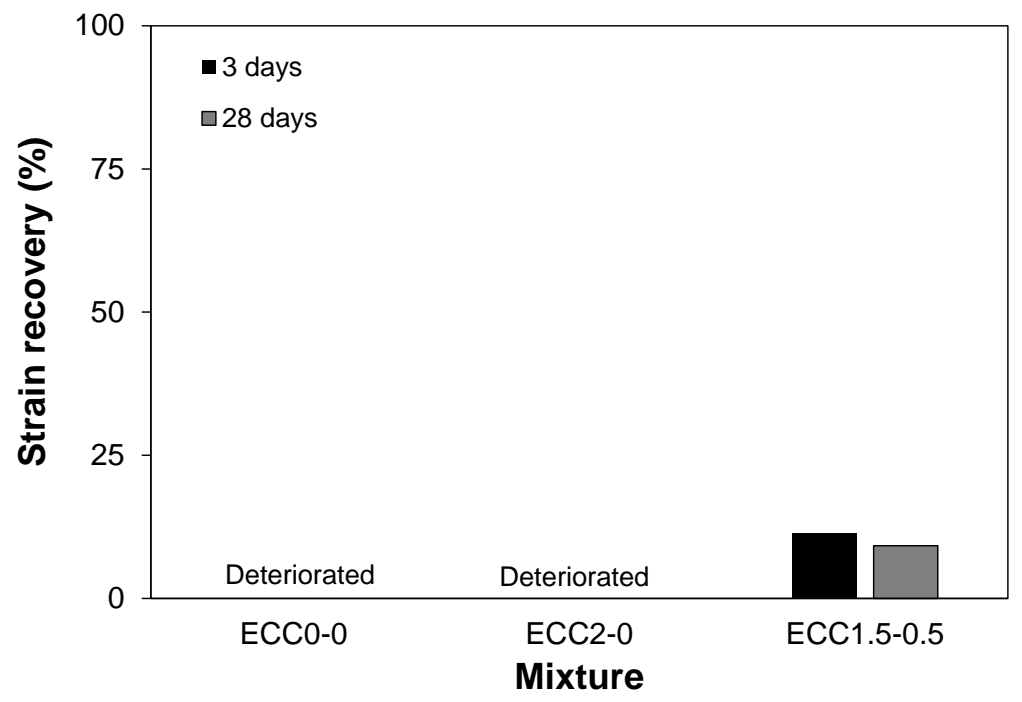

Figure (5): Percent enhancement in recovery strain of ECC cracked specimens.

Figure 5 exhibits the strain recovered by ECC specimens after heat treatment. For instance, the average crack width at the tensile face of the ECC1.5-0.5 specimens was decreased by about $11.4 \%$ and $9.2 \%$ for specimens tested at 3 and 28 days, respectively, due to the heating process compared to that of similar non-heated specimens. This phenomenon shows the uniqueness of the self-centering ability of SMA fibres. The ECC matrix specimens as well as the PVA-ECC specimens did not show any recovered strain and incurred more deterioration due to heating. It can be concluded that the heat treatment process was an effective method that can be used to stimulate the SMA effect of the fibres, consequently healing the cracks due to shape memory effect.

\section{Conclusions:}

The experimental investigation conducted in this study aims to explore the effects of partial replacement of PVA with $0.5 \%$ SMA fibres by volume fraction on the workability, compressive and splitting tensile strength, and flexural behaviour of ECC at 3 and 28 days. The following conclusions can be drawn based on the experimental results.

- Generally, the workability of ECC decreased due to fibre addition compared to that of the ECC matrix mixture, regardless of the fibre type. Furthermore, partial replacement of PVA with $0.5 \%$ SMA fibres led to a reduction in workability by about six times that of the ECC incorporating 2\% PVA fibres alone.

- A slight to no increase in compressive strength of the composite was observed due to SMA and/or PVA fibre addition at all testing ages. 
- Generally, the tensile capacity of the ECC composite was improved due to fibre addition. Likewise, the tensile capacity of the fibre-reinforced ECC composite was increased due to partial replacement of PVA with SMA fibres $(0.5 \%$ by volume fraction) and when the curing age was prolonged.

- An overall enhancement in the flexural capacity of the composite was observed due to fibre addition compared to that of ECC matrix mixture. However, a slight reduction in flexural capacity was observed due to the replacement of SMA with PVA fibres all testing ages.

- Strain recovery was achieved by heat treatment owing to the healing of cracks in the ECC specimens which incorporate 0.5\% SMA fibres due to the shape memory effect. On the other hand, an overall deterioration was observed in the other specimens made with and without PVA fibres alone due to heat treatment.

\section{References:}

[1] ASTM C150/C150M, Standard Specification for Portland Cement, American Society for Testing and Materials, ASTM International, West Conshohocken, USA, 2015.

[2] ASTM C1609/1609M, Standard Test Method for Flexural Performance of FiberReinforced Concrete (Using Beam with Third-Point Loading), American Society for Testing and Materials, ASTM International, West Conshohocken, USA, 2012.

[3] ASTM F2063, Standard Specification for Wrought Nickel-Titanium Shape Memory Alloys for Medical Devices and Surgical Implants, American Society for Testing and Materials, ASTM International, West Conshohocken, USA, 2012.

[4] ASTM C230/C230M, Standard Specification for Flow Table for Use in Tests of Hydraulic Cement, American Society for Testing and Materials, ASTM International, West Conshohocken, USA, 2014.

[5] ASTM C39/C39M, Standard Test Method for Compressive Strength of Cylindrical Concrete Specimens, American Society for Testing and Materials, ASTM International, West Conshohocken, USA, 2015a.

[6] ASTM C494/C494M, Standard Specification for Chemical Admixtures for Concrete, American Society for Testing and Materials, ASTM International, West Conshohocken, USA, 2015a.

[7] ASTM C496/C496M, Standard Test Method for Splitting Tensile Strength of Cylindrical Concrete Specimens, American Society for Testing and Materials, ASTM International, West Conshohocken, USA, 2011. 
[8] ASTM C618, Standard Specification for Coal Fly Ash and Raw or Calcined Natural Pozzolan for Use in Concrete, American Society for Testing and Materials, ASTM International, West Conshohocken, USA, 2015.

[9] M. Nehdi, A. Shahria, and M. Youssef, Development of Corrosion-Free Concrete Beam-Column Joint with Adequate Seismic Energy Dissipation. Engineering Structures, Vol. 32, No. 9, P. 2518-2528, 2010.

[10] M. Nehdi, and J.D. Ladanchuk, Fiber Synergy in Fiber-Reinforced SelfConsolidating Concrete, ACI Materials Journal, Vol. 101, No. 6, P. 508-517, 2004.

[11] M. Wu, B. Johannesson, and M. Geiker, A review: Self-healing in cementitious materials and engineered cementitious composite as a self-healing material, Construction and Building Materials, Vol. 28, No. 1, P. 571-583, 2012.

[12] X. Li, M. Li, and G. Song, Energy-dissipating and self-repairing SMA-ECC composite material system, Smart materials and structures, Vol. 24, No. 2, P. 1-15, 2015.

[13] Z. Pan, C. Wu, J. Liu, W. Wang, and J. Liu, Study on mechanical properties of cost-effective polyvinyl alcohol engineered cementitious composites (PVA-ECC), Construction and Building Materials, Vol. 78, No. 1, P. 397-404, 2015. 